Doi: https://doi.org/10.31578/jebs.v6i2.234

\title{
The Self-perceived Impact of COVID-19 Human Mobility Restrictions on Armenian Students Aged 14-18
}

\section{Garik Poghosyan*}

\begin{abstract}
The present article showcases the self-perceived impacts of COVID-19-related human mobility restrictions on the Armenian youth aged 14 to 18. Rather than attempting to discuss policies or theories or concentrate on certain areas of the fabric of human society, such as human rights, economy, health care, this case study makes a bold attempt to illuminate the reader about the condition and self-perceived effects of the crisis on a specific age group in the context of COVID-restricted mobility and ensuing challenges (education, social life, including sports and extracurricular activities, emotional well-being) in a given country, something that has been prevailingly, if not completely, ignored even in those research projects that have addressed the COVID19-related human mobility limitations for specific groups of people (migrants, the displaced, women, etc.). Thus, the author has attempted to lay the groundwork for further case studies as well as comparative research investigating the human mobility dimension of the COVID-19 crisis for adolescents or various age groups with an emphasis on the effects of reduced or restricted mobility on the intellectual, athletic, social or cultural life of those affected by them. Overall, the participants displayed the whole gamut of both negative and positive experiences and gave varied responses.
\end{abstract}

Keywords: human mobility, COVID-19, students aged 14-18

\section{Introduction}

COVID-19 has raised important questions concerning issues in the realm of human mobility. Since March 2020, the Republic of Armenia officially entered a phase of regulating human mobility. On March, 17, the country officially prohibited organizing any activities, events or regular programs that involved at least twenty people in the domains of culture, sports and education. ${ }^{2}$

As a follow-up, the country instituted a new human mobility regime "limiting the right of people to move." ${ }^{3}$ As of July 30 , the country still continued establishing further restrictions in the area of economic activities. ${ }^{4}$ Thus, it has become necessary to obtain and analyze data regarding the effects of human mobility restrictions for various groups, such as the unemployed, women, the disabled, the working poor, rural and urban populations, the retired, etc. As far as our research has demonstrated, to date there have been no attempts to collect such data, analyze, interpret and publicize them. Thus, the purpose of the present paper is to become a springboard for broader and deeper research initiatives in this field and to lay the groundwork for further research and policy recommendations during and after the COVID-19 crisis in the field of education and youth policy.

\footnotetext{
* MA. Global Bridge Educational Complex, Yerevan, Armenia Corespondiong Email: garik.poghosyan2011@gmail.com ${ }^{2}$ Decision of the Armenian Government, March 17, 2020 https://www.gov.am/files/docs/3951.pdf

${ }_{3}^{3}$ Decision of the Armenian Government, March 24, 2020 https://www.gov.am/files/docs/3969.pdf

${ }^{4}$ Decision of the Armenian Government, July 30, 2020 https://www.gov.am/files/docs/4273.pdf
} 
Against this backdrop, we have decided to focus on the age group 14 to 18 based on two main considerations. First, due to our work-related responsibilities we have deemed it possible to acquire valid data from this age group although working professionals could also have been a target group. Second, as students aged 14 to 18 prepare for high school and university exams as well as prepare for the army - in the case of male citizens - or are going through the important stage of choosing their future profession, their emotional well-being and immediate concerns become of paramount importance at least for educators and parents. Interestingly, human mobility restrictions have now come to be interpreted in a wider context. Amit and Salazar (2020) state that "since the beginning of the new millennium, the emergence of a contemporary interdisciplinary field of mobility studies has shifted away from a linear conception of moving or a priori assumptions of sharp demarcations between different types of journeys" (p.8).

In this very context, we attach a great value to the study of human mobility implications for adolescents as they approach important intellectual and athletic milestones. Not surprisingly, some experts argue that "we should of course analyze in detail the social conditions which made the coronavirus epidemic possible" (Refugees International, 2020). To situate our research within a broader universal picture of scientific inquiry we have aimed at discovering patterns and making recommendations that can be tested and verified elsewhere in the world for the same age group and within the COVID-19 boundaries.

To be precise, "in this globalized age, the world community expects accurate, complete, and timely information about diseases that do not respect international borders" (World Health Organization, 2006). We are certain that an innovative research can pave the way for better policies and a better understanding of the challenges posed by COVID-19-related human mobility restrictions as "intelligence agencies and conservative think tanks have classified infectious diseases as a "nontraditional threat" to national and global security" (Snowden, 2019). It is with this understanding that we designed and carried out this research project hoping to make a contribution at this earliest stages of developing data-driven professional literature regarding the effects of restricted human mobility on the lifestyle and overall well-being of adolescents. We assumed that it is the responsibility of each and every one among social science and medical researchers as well as educators to spare no efforts establishing scientific paths to universally feasible COVID-19 solutions. Global health-related challenges are increasingly likely as "since 1971, scientists have discovered at least 25 new pathogens for which we have no vaccine and no treatment" (Quick \& Fryer, 2018, p.53).

In line with this fact, it is argued that "national governments are responsible for protecting their citizens, but they can't succeed by fiat. International organizations like WHO, scientific organizations like the CDC, economic organizations like the World Bank, private-sector companies, faith-based organizations, and thousands of NGOs also help in a crisis and keep essential services operating" (Quick \& Fryer, 2018, p. 129 ).

To sum up, the author of the present paper hopes to open an academic forum of research and discussion through this article regarding the future responses to challenges posed by COVID-19 or other health crises for a vulnerable age group-14 to 18- transitioning from adolescence to adulthood.

\section{Literature Review}

The relationship of human mobility with the perceived, observable or documented impact of the pandemic during the on-going Covid-19 crisis has been the focal point of many a research project recently. Scholarly attention has been directed towards multiple dimensions of the issue. Some authors have referred to data collection as a means to establish human mobility patterns in a given geographic area, for example, the European Union. To be precise, "on 8 April the European Commission asked European Mobile 
Network Operators (MNOs) to share anonymized and aggregated mobile positioning data. These data would provide mobility patterns of population groups" (Santamaria et al., 2020, p.7).

The project set itself important goals, such as explaining "the correlation between the confinement measures designed to prevent the spread of COVID-19 and mobility" as well as "feed models to estimate the economic costs of the different interventions, as well as the impact of specific control measures on intra-EU cross border flows due to the epidemic." (Santamaria et al., 2020). Nevertheless, the authors did not aim to provide any relevant data or analysis for a specific age group or another segment of the population. Further, lacus et al. (2020), in a more country-specific data analysis initiative, came to certain conclusions regarding France, Italy and Spain stating that, "this report demonstrates that human mobility, derived by mobile data, is highly correlated with the spread of COVID-19 in the initial phase of the outbreak. In the case study of France, we have found that mobility can explain from $52 \%$ up to $92 \%$ of the excess deaths reasonably linked to the COVID-19 outbreak. In the case study of Italy, we have found similar results" (p.2). These case studies also demonstrate the impact and correlation of human mobility on the spread of the disease without reference to any vulnerable or affected segments of the population.

Others made an attempt to link the COVID-19 crisis to food security and underscored its special significance for vulnerable populations. To be specific, "The COVID-19 crisis has highlighted the need to provide food security to migrants around the world. In India, the key policy to provide food security, i.e., ration card portability, has come under the national spotlight..." (Choudhury et al., 2020, p.7). The authors claimed to" find that food distribution activities by local ration shops and civil society actors (as estimated based on daily news reports) are associated with reductions in both intra-state and inter-state mobility. This result suggests that local food distribution is a critical complement to formal policies in ensuring food security for migrants during the crisis. The finding also highlights the broader role of civil society actors in developing countries, where they can provide crucial support beyond that provided by the state" (Choudhury et al., 2020, p.7).

Yet another study focused on travel behavior in general in the UK: "A notable drop in people driving and using public transport in the UK was observed from 8th March 2020. This observation may indicate that the government's press release on this date, outlining the COVID-19 Emergency Bill and plans to move from 'contain' to 'delay' the COVID-19 progression, had a direct impact on travel behavior"(Hadjidemetriou, 2020, p. 3). Even though this targets a specific human mobility dimension in a particular context, it does not offer any focus in terms of age groups. In a similar fashion, some authors illustrate human mobility issues in the context of human rights specifying non-discrimination, health, movement across states, immigration policy, privacy, gender and marginalized groups (Refugees International, Report, 2020), which is apparently the most comprehensive umbrella study investigating various aspects of human mobility restrictions during the COVID-19 crisis. The authors of the report also provide a well-grounded rationale behind looking into different directions of the topic by stating that "in responding to the COVID-19 pandemic, many States have taken harsh and unprecedented measures against migrants, refugees, and other displaced persons. These have included border closures, quarantines, expulsions, and lock-downs of migrant worker communities and refugee camps. Migrants, refugees, and other displaced persons have also been excluded from programs adopted by States to secure the health and economic well-being of those within their borders" (Refugees International, 2020, p.4). In a departure towards more policy and migration-related scholarly concentration, some authors come to a well-informed conclusion that "the environment is dynamic and changing rapidly. There is a high level of uncertainty regarding the future of global border management and immigration policies and systems, and a range of flexible and innovative solutions will need to be implemented and adjusted by governments at national and regional levels based on existing and emerging evidence about the pandemic, as well as the effectiveness of various medical, public health and social response measures."(UN Migration Policy Paper, 2020, p. 2). Obviously, whether scholarly inquiry aims to examine specific countries through case studies, vulnerable groups, such as migrants 
or broader topics like the public transport system and human mobility, they largely overlook both the importance of concentrating on certain age groups and education, more precisely, secondary education.

In a similar fashion, the UN Policy Brief on COVID-19 and People on the Move discusses in-bound and out-bound travel behaviors stating that "the number of international migrants at mid-2019 is estimated to be around 272 million persons, defined for statistical purposes as persons who changed their country of residence, including refugees and asylum-seekers" (UN, 2020, p. 5). Moreover, it claims that "IDPs, refugees and many migrants, especially those in vulnerable situations, also face barriers to accessing health services due to various factors, including their migration status, lack of awareness or social protection, costs, language, disability, gender norms and cultural barriers, or as a result of discriminatory laws, policies and practices" highlighting the intricate health hazards various human groups encounter worldwide. In addition, the policy brief draws attention to social and economic issues accentuating "reduced incomes, increasing unemployment, as well as increasing expenses and price hikes for basic commodities" (p. 11) as well as "gender-based violence, in particular intimate partner violence exacerbated by confinement and lockdown measures" (p. 14), but still falls short of either discussing the implications of the crisis for specific age groups or secondary and post-secondary education. Thus, our aim in this article was to start a discussion about the impact and far-reaching consequences of COVID-19-related human mobility restrictions for students aged 14-18 through a case study in Armenia hoping to trigger similar case studies and comparative studies elsewhere to evaluate the conditions of various age groups, in particular, under-age or adult students have had to cope with.

\section{Method}

Our research is methodologically qualitative, based on surveys with open-ended questions. The selection of the participants was based on a general criterion of being involved in extra-curricular activities related either to personal growth or to foreign language acquisition during or immediately prior to the survey. Other criteria, such as age, gender distribution, income brackets, educational background, geographic location of permanent residence, were not considered before the selection of the participants and thus any conclusions pertaining to those domains can be inconsistent.

Participants

Initially, thirty students aged 14 to 18 were selected to be contacted for the purpose of the survey, overwhelmingly through email. A few students were contacted through social media additionally. The email addresses were available through the student database of Global Bridge Educational Complex in Yerevan, Armenia or our personal contact list. Half of the contacted students responded positively agreeing to answer the open-ended questions in writing and submit the answers electronically. One student responded negatively while fourteen others did not respond at all. Due to the limited mobility options and access to the Internet in geographic locations outside Yerevan, we cannot confirm if those who did not respond received the email or simply ignored it, as we have no information regarding their whereabouts during the summer vacation and did not make attempts to contact them by phone.

In the end, twelve students responded within a reasonable time-frame and thus their answers were collected as data for the purpose of this paper. The students were selected based on one chief criterion - participation in at least one extra-curricular program (language courses, math, professional orientation and counselling) in addition to belonging the appropriate age group (due to the availability of contact data as well as presumed high mobility). Seven students attended private schools at the time of submitting the responses while five attended public schools. The students attended a total of six schools. Six of the schools are located in Yerevan while one of them is based in the town of Artashat. Two of the students wouldl continue their studies in other 
private schools in Armenia and England in the academic year 2020-2021. If the two new schools are to be counted, the total number of schools the students were enrolled in rise to eight. Thus, they tended to self-identify as students of both. The breakdown of age groups is as follows: two students were fourteen years old, three students were fifteen, three of them sixteen, three seventeen and one student was eighteen.

\section{Research Instrument}

In addition to filling in personal data - age and school affiliation - the students had to respond to four main questions regarding the mobility-related issues they had been experiencing due to COVID-19. The open-ended questions were chosen to avoid inhibiting the students in terms of evaluating their experiences and exposing their perceptions concerning the impact of COVID19 restrictions on their overall mobility and related effects. Consequently, the analysis of the data presented in four sections is based on the distinct evaluative questions of the survey.

\section{Limitations}

It should be noted that, due to the time-frame, the scope and depth of this research, there are certain limitations to be considered. First, the study focused on students who have previously demonstrated a keen interest in extra-curricular activities; hence they might be more or less affected by the changes, more or less prepared emotionally, academically or otherwise compared to less active members of the peer group. Second, all the students who took part in the survey permanently resided in the capital of the Republic of Armenia, Yerevan apart from one student who resides in the town of Artashat. Consequently, the present paper does not purport to represent the self-evaluations, perceptions or observations of smaller or less developed towns in the country. Further, it does not reflect the attitudes of various income brackets: while not all student participants attended or intended to attend private schools, eight students did, while two others attended a highly selective public school and all of them, as was discussed earlier, took part in a combination of paid and unpaid extra-curricular programs which is a strong indication to the fact that most of them were expected to come from upper middle-class families.

\section{Discussion of Results}

Question 1: To what extent has coronavirus impacted your mobility (school, extra-curricular activities, athletics, and travel)?

Generally, the students tend to agree that COVID-19 has had a negative impact on their mobility with responses from "somewhat" to "extremely negative". The responses include both referrals to academic achievements as well as extra-curricular life and athletics. Some students discussed travel arrangements as well as gave evaluative responses regarding the impact the limited mobility had on their intellectual life and personal interests. For instance, one of the students described online lessons as less effective. In a similar vein, another student described online lessons as tedious, which is more of an educational evaluation than mobility-related. However, whether the evaluations were positive or negative regarding online lessons, they were viewed as corollaries of limited mobility and ascribed to the legally enforced conditions due to COVID-19. Some of the responses involved more depressive contents, such as "I have forgotten about all activities, sports and travel arrangements". Yet another student stressed that the school schedule had been subject to changes which resulted in their falling behind the curriculum. Two others claimed they led passive lifestyles and gave up sports - basketball and swimming. The only positive statement came from a student whose school organized trips to the countryside in small groups which came as a relief after all travel cancellations. To conclude, even though the evaluations varied, they tend to concur that COVID-19-related restrictions have had a negative influence on their 
mobility, which, in its turn, has had repercussions in the domains of education, athletic life, travel, other interests and has, in some cases, resulted in changes in lifestyle and repetitive mood swings.

Question 2: What factors have had a positive or negative influence on your mobility (restrictions, public transport, cancelled classes, delayed plans, online lessons, or new opportunities)?

Even though the experiences of the students were prevalently similar, they varied in terms of perceptions and focus. The students highlighted the physical and academic implications of lack of mobility as the main focal points of their concerns. One of the students said they "used to walk a lot with friends after classes", something that was drastically reduced. In a similar fashion, a student argued that his body "would not submit to control." Further, a student mentioned the impossibility of volunteering because of the restrictions as an example of a negative influence on mobility. A student rather humorously referred to the cancellation of end-of-year exams in schools as a positive influence COVID-19 restrictions had. Nevertheless, a few students also came up with positively charged answers. To be specific, two students mentioned having more time to do reading as well as taking up a new foreign language. However, the somewhat extreme view of one of the participants seems to capture the overall feeling: "mobility is at an all-time low." Interestingly, instead of mentioning specific factors, the students continued to give general descriptions of their lifestyle choices, difficulties, cancellations and deficient academic progress against the backdrop of COVID19. More importantly, even though some of the evaluations tended to be slightly divergent due to personal circumstances ("I cannot use the public transport system" described as a negative factor or "I have never used the public transport system much" as a factor of secondary importance), they tended to widely agree that there are several negative factors but there are no positive ones. This leads us to conclude that reduced or limited mobility has resulted in a significant number of changes in the routine and academic and athletic goal-setting of the teenage participants of the survey, and, by extension, the wider adolescent population.

\section{Question 3: To what extent have the mobility restrictions impacted your academic progress or your emotional well-being?}

The responses to this question are variegated but display a more visible bifurcated pattern in terms of the student evaluation of academic progress and emotional well-being. Interestingly, students tend to believe that restrictions had little if any negative impact on their progress. Some of the self-evaluations were even positive with regards to educational capacity-building and their overall positive attitudes revealed their appreciation of having had to spend no time commuting and being capable of taking up new hobbies or embark on fresh learning journeys from the comfort of their homes. However, the students seem to overwhelmingly agree that the restrictions have caused certain emotional issues which, to varying degrees, have influenced their emotional state in rather negative ways. Not surprisingly, only one student declared that the restrictions had "absolutely no" effect on his academic progress of emotional condition. Others gave more specific evaluations in the wider picture of either negative or neutral/positive descriptions. One of the students talked about a new hobby - photography - that she had taken up as she had much more free time at her disposal. Nevertheless, the student mentioned that online classes had further worsened her eye-sight, something that indicates the possible visual health implications for students spending hours in front of the screens of their computers or other gadgets as online classes become a norm rather than an alternative or additional support mechanism in the field of secondary education. In contrast to most responses that tended to minimize or completely ignore the possible negative impact of the mobility restrictions on their studies, one of the students said she lacked "almost any fountain of motivation" to study and, at the same time, depicted her emotional state as tense and passive. Another student reinforced this evaluation by stating, "I am becoming more perturbed staying at home." In a departure from more moderate or closely related views, one of the students claimed that, even though the restrictions had had a positive impact on her studies, they had had "an unspeakably negative" influence on her emotional well-being. She went on to explain that "there is a higher risk of stress" as they are confined 
to homes. Interestingly, another student mentioned that in the beginning it was emotionally difficult for him to stay at home, but later he adapted to the new regime. This raises the question of the adaptability of students to new, challenging conditions and environments that can be the corollary of unpredictable situations similar to the challenge of COVID-19-related human mobility restrictions. One of the students ignored the possibility of the restrictions having had a negative educational impact, but complained about the dearth of connections with friends. In line with this, one of the students observed that, after the lockdown was instituted, people "have become more timid to communicate with each other face to face." This observation, in conjunction with earlier remarks, lead us to understanding the long-term effects of human mobility restrictions during the pandemic in terms of relationships, communication, friendships, their frequency, quality, and possibilities to bond and socialize with peers, things that, we assume, can result in permanent social norms and patterns or impact the psychological dimension of the well-being of those who have been affected by the enforced alterations in their mobility regimes.

\section{Question 4: What measures would you like the government or NGO-s to and the private sector to take in order to boost your mobility?}

Interestingly, none of the students referred to the private sector or NGOs: there were no expressed expectations, suggestions, complaints or commending evaluations when it comes to those. Concerning the measure the government should take, some students mostly limited their responses to general evaluations of what the government has already done giving overwhelmingly positive assessments (they have already "gone to great lengths to provide us with safety"; "I am content"; "everything is being done in the right way"). It should be noted, however, that we have made no attempt to discover to what extent these evaluations reflect the influence of the families, teachers or the media. In contrast, several students had specific expectations. For instance, one of the students said, "I would like to replace online education with the attendance of traditional classes. For example, mandatory check-ups before entering educational institutions could be instituted. If students feel fine, they should be allowed to participate in the class." Another student made a similar expectation: "I believe educational institutions should reopen in September as educational shortcomings might not be addressed while other institutions ought to gradually reopen sticking to the prescribed norms." Obviously, the two students are concerned about the prospects of the quality of education. Further, they seem to see no reason why strict prohibitions - school closures - should be in place if there are preventive rules that can be strictly observed. Other students came up with similar recommendations that mostly refer to either easing the restrictions or regulating human mobility with stricter rules. For example, one of the students said "lifting the restrictions is the only option" apparently referring to the measures taken by the government. In a similar fashion, two of the participants wished the compulsory wearing of masks was reconsidered as one of them went so far as to claim that "it has repeatedly been proven they are pernicious." Meanwhile, another student suggested stricter regulation of human mobility and heavier fines for those who break the rules. It should be noted, however, that this observation was an exception, as even those who were satisfied with the current state of affairs did not expect further restrictions or more regulations. Thus, it is safe to conclude that even though some of the participants are eager to see schools reopen and restrictions being increasingly removed, there are those who do not have specific suggestions or expectations, are satisfied with the efforts made on the part of the government, which is a demonstration of the fact that there is no consensus regarding the removal, maintenance or tightening the various measures that have been in place.

\section{Conclusion}

To sum up, the results obtained from our research have raised more important questions than provided answers. First, we believe it is necessary to target both deprived city areas as well as the provinces of Armenia to compare the experiences of the youth in 
the context of recent human mobility restrictions. Second, it is necessary to conduct similar research in other geographic locations and to compare the findings obtained from the same age group but different countries. At this stage, we are unable to hypothesize if age has been the most important factor in terms of the experiences and perceptions discussed earlier or income or culture matter more. Further, we have no opportunity to compare developing countries with developed nations and come to internationally relevant conclusions. Third, unfortunately, our research has been limited in terms of the number of participants and the general description of the participants (expectedly form upper middle class families, actively engaged in extracurricular activities, overwhelmingly from Yerevan-based highly selective private and public schools). More important, I order to arrive at broad conclusions the scientific community needs to engage doctors, psychologists, parents and, perhaps most importantly, educators to judge the effects of short- and long-term physical, emotional, educational, communicative, cultural effects of COVID19-related mobility restrictions for the targeted age group. Our work has been further complicated by the fact that it is unprecedented within its own boundaries - COVID-19-related human mobility challenge for people aged 14 to 18 in Armenia and its perceived repercussions. Therefore, we trust our research is a stepping stone towards more comprehensive, multi-layered, internationally relevant, glocal, multi-disciplinary research projects and provides some clues and an overall direction, but exceptionally few definitive answers. The few answers that our research has provided against the backdrop of all the limitations exposed earlier are the following, which might serve both as conclusions, policy recommendations and statements leading to further research ("young people" is used as a generalization to refer to the participants in an attempt to extend the scope of the study towards universalism):

$\checkmark$ Young people do not tend to victimize themselves in the face of human mobility restrictions and tend to combine negative and positive evaluations in overtly rational attitudes and well-balanced judgments;

$\checkmark$ It is unknown to what extent income, family background, culture and origin have contributed to the views expressed and if age is the dominant factor across income groups and countries;

$\checkmark$ Young people make an attempt to exploit opportunities, such as taking up new hobbies, learning languages or doing more reading but, depending on circumstances and personality types, also declare giving up on favorite sports and notice the inadequate amount of communication with their peers;

$\checkmark \quad$ The emotional well-being of people aged 14-18 has been damaged significantly with most of them feeling apparently depressed, experiencing lack of motivation, having a foreboding feeling of stress, feeling "tense";

$\checkmark$ The emotional negativity of COVID-19-related human mobility restrictions greatly surpasses the perceived effects on academic performance (although the evaluations have relative validity as teachers' assessments are not included);

$\checkmark$ Young people either ignore, are incognizant of or distance themselves from having expectations from the private sector or with an exception to prove the rule - NGOs (it is unknown whether this is peculiar to the Armenian context) when it comes to support or assistance;

$\checkmark$ Young people are wary about the effectiveness of online classes, tend to prefer traditional classes and are generally flexible to incorporate new pandemic-related rules for the purpose of attending classes in person;

$\checkmark$ Abrupt changes and pervasive passivity are considered negative factors possibly ameliorated by planned or selfstarted support schemes (learning something new, going on excursions, have more time and energy to heed attention to classes etc.). 
Based on the above-mentioned outcomes, we find it safe to assume that young people do not perceive a significant negative impact on their academic achievements on the part of COVID-19 mobility constraints (within the framework of this research), something that must be corroborated by expert opinions and standardized test results and perhaps reinforced through longitudinal studies to become an established fact. Further, young people have been hit harder emotionally, which leads us to the discussion of the necessity to look into the possibility of formal psychological assistance in school settings, offering alternatives to their built-in routines and addressing their perceived or actual falling behind in their favorite athletic and intellectual domains. Last but not least, further collaborative and rigorous research is required to formally respond to questions/hypotheses arising from this article. 


\section{References}

Amit, V. \& Salazar, N.B. (2020). Pacing Mobilities: Timing, Intensity, Tempo and Duration of Human Movements. New York: Berghahn Books.

Choudhury, P., Koo, W.W., Li, X., Kishore, N., Balsari, S., \& Khanna, T. (2020). Food Security and Human Mobility during the COVID19 Lockdown: Working Paper 20-113; 2020, Harvard Business School.

Hadjidemetriou, G.M., Sasidharan, M., Kouyialis, G, \& Parlikad, A.K. (2020). The impact of government measures and human mobility trend on COVID-19 related deaths in the UK. The Journal of Transportation Research: Interdisciplinary Perspectives, 6. DOI: 10.1016/j.trip.2020.100167

lacus, S.M., Santamaria, C., Sermi, F., Spyratos, S., Tarchi, D., \& Vespe, M. (2020). How Human Mobility Explains the Initial Spread of COVID-19, A European Regional Analysis, JRC Technical Reports. Luxembourg: EU.

Quick, J.D. \& Fryer, B. (2018). The End of Epidemics: The Looming Threat to Humanity and How to Stop It. New York: St. Martin's Press.

Refugees International. (2020). Human mobility and human rights in the COVID-19 pandemic: Principles of protection for migrants, refugees, and other displaced persons. Report Developed under the Auspices of Columbia University, Cornell Law School, Zolberg Institute on Migration and Mobility. Retrieved from https://www.refugeesinternational.org/reports/2020/4/29/14-principles-of-protection-for-migrants-and-displacedpeople-during-covid-19

Santamaria C., Sermi, F., Spyratos, F., lacus, S.M., Annunziato, A., Tarchi, D., \& Vespe, M. (2020). Measuring the impact of COVID19 confinement measures on human mobility using mobile positioning data: A European regional analysis. Safety Science, 132. https://doi.org/10.1016/j.ssci.2020.104925

Snowden, F.M. (2019). Epidemics and Society: From the Black Death to the Present. London, OK: Yale University Press.

United Nations. (2020). COVID 19 and People on the Move; Policy Brief. Retrieved from https://unsdg.un.org/resources/policybrief-covid-19-and-peoplemove\#: :text=COVID\%2D19\%20leaves\%20few\%20lives,vulnerable\%20situations\%20before\%20the\%20crisis.\&text=The \%20disproportionate\%20impact\%20of\%20the,interlocking\%20crises\%2C\%20exacerbating\%20existing\%20vulnerabilities

United Nations International Organization of Migration. (2020). Cross-Border Human Mobility Amid and After COVID-19; Policy Paper. Retrieved from https:/www.iom.int/sites/default/files/defaul/pp crossborder human mobility amid and after covidCOVID-19 policy.pdf

World Health Organization. (2006). SARS: How a Global Epidemic Was Stopped. Geneva, Switzerland: WHO. Retrieved from https://apps.who.int/iris/bitstream/handle/10665/207501/9290612134_eng.pdf?sequence=18isAllowed=y 